\title{
Infrared Reflection-Absorption Spectroscopy and Density Functional Theory Investigations of Ultrathin ZnO Films Formed on Ag(111)
}

\author{
Mie Andersen, ${ }^{*,}, \dagger$ Xiaojuan Yu, ${ }^{\S, \ddagger}$ Matthias Kick, ${ }^{\dagger}$ Yuemin Wang, ${ }^{*, \$}$ Christof Wöll, ${ }^{\dagger}$ \\ and Karsten Reuter ${ }^{\dagger}$ \\ ${ }^{\dagger}$ Chair for Theoretical Chemistry and Catalysis Research Center, Technische Universität München, Lichtenbergstraße 4, 85747 \\ Garching, Germany \\ ${ }^{\ddagger}$ Institute of Functional Interfaces, Karlsruhe Institute of Technology, Hermann von Helmholtz Platz 1, 76344 \\ Eggenstein Leopoldshafen, Germany
}

\begin{abstract}
Reactivity at metal oxide interfaces is of fundamental importance in heterogeneous catalysis. Herein, we report a thorough surface science study on the growth and chemical activity of ultrathin $\mathrm{ZnO}$ films on $\mathrm{Ag}(111)$ by grazing emission $\mathrm{X}$ ray photoelectron spectroscopy and temperature dependent infrared reflection-absorption spec troscopy using $\mathrm{CO}$ as a probe molecule. Compared to bilayer $\mathrm{ZnO}$ on $\mathrm{Cu}$ [Schott, V.; Angew. Chem. Int. Ed. 2013, 52, 11925-11929], we find a much decreased CO binding energy of $0.24 \mathrm{eV}$ for bilayer $\mathrm{ZnO}$ on Ag. Furthermore, the anomalous, substantial red shift of the $\mathrm{CO}$ stretch frequency with respect to the gas phase value identified for $\mathrm{ZnO} / \mathrm{Cu}$ is absent in the $\mathrm{ZnO} / \mathrm{Ag}$ system, where we instead report a slightly blue shifted frequency at $2146 \mathrm{~cm}^{-1}$ for isolated $\mathrm{CO}$ molecules. In order to interpret these differences of $\mathrm{ZnO}$ thin layer supported on these two coinage metals, we carried out a thorough theoretical analysis using density functional theory calculations employing van der Waals corrected generalized gradient approximation (GGA) type and hybrid functionals. We show that bilayer $\mathrm{ZnO}$ forms a flat graphitic like structure on $\mathrm{Ag}$ in contrast to the previously reported strongly corrugated $\mathrm{ZnO}$ film formed on $\mathrm{Cu}$. While our results show that GGA type functionals cannot in general be applied uncritically for CO adsorption on $\mathrm{ZnO}$, we explicitly validate our results for the $\mathrm{ZnO} / \mathrm{Ag}$ system by comparison to hybrid functional calculations for selected model systems.
\end{abstract}

\section{INTRODUCTION}

The tendency of certain oxides to wet the surfaces of metals has been intensively studied, both as carefully prepared model systems for surface science investigations as well as in the context of their spontaneous formation in real catalytic systems. $^{1-7}$ While such oxidic thin films often cause an undesired blocking of active metal sites, they have in several cases been shown to contribute beneficially toward the stability, selectivity and/or activity of catalysts. ${ }^{2-5}$ The unusual proper ties of ultrathin metal-supported oxide films have been interpreted in terms of their significantly altered structure and adsorptive properties compared to the bulk oxide ${ }^{1}$ as a consequence of strong metal-support interactions (SMSI).

Among the studied catalytic systems exhibiting SMSIs, ultrathin films of zinc oxide on metals have received particular attention owing to their potential importance and applications as catalysts for methanol synthesis, the water gas shift reaction, and $\mathrm{CO}$ oxidation. ${ }^{2,8-14}$ Whereas bulk $\mathrm{ZnO}$ crystallizes in the wurtzite structure, thin films of this interesting oxide have been predicted to form layered, graphitic structures, $\mathrm{ZnO}_{(\mathrm{gr})}$, with a layer stacking as in $\mathrm{h} \mathrm{BN} .^{15}$ Previously, we have shown that a thin $\mathrm{ZnO}$ film grown on brass(111) adopts a distorted structure in between the ideal wurtzite $(0001)$ and the planar $\mathrm{ZnO}_{(\mathrm{gr})}$ structure. ${ }^{10}$ It was found that this new thin film phase of $\mathrm{ZnO}$ exhibits $\mathrm{Zn}$ atoms with a lowered oxidation state, which significantly enhanced the bonding of $\mathrm{CO}$ to the film. As a fingerprint of the modified chemical reactivity of the film, an anomalous red shift by about $70 \mathrm{~cm}^{-1}$ relative to the normal stretch frequency for $\mathrm{CO}$ adsorbed on wurtzite $\mathrm{ZnO}$ was observed. Interestingly, a similar red shift has recently been observed in an industrial type $\mathrm{Cu} / \mathrm{ZnO}$ catalyst for methanol synthesis from $\mathrm{CO}_{2}$ and $\mathrm{H}_{2}{ }^{11}$ This $\mathrm{CO}$ frequency was assigned to an adsorption site characterized by a partial coverage of the copper nanoparticles in the catalyst by a thin layer of metastable, defective zinc oxide, similar to the model catalyst investigated in ref 10 , and in agreement with previous 
observations of such structures in industrial type $\mathrm{Cu} / \mathrm{ZnO}$ catalysts by transmission electron microscopy (TEM).

Apart from the catalytic applications of ultrathin $\mathrm{ZnO}$ films on metals, it is also of fundamental interest to understand the origins of their modified adsorptive properties and in particular the role of the underlying metal substrate. In addition to $\mathrm{ZnO}$ films grown on $\mathrm{Cu},{ }^{10,16}$ the growth on a number of other metallic substrates has also been realized, including $\mathrm{Ag},{ }^{17-19}$ $\mathrm{Au}^{20,21} \mathrm{Pt}^{12}$ and $\mathrm{Pd}^{22}$ The role of the metal substrate for the structure of thin $\mathrm{ZnO}$ films has been studied in great detail using density functional theory (DFT). ${ }^{23}$ The DFT results from ref 10 demonstrated that $\mathrm{ZnO}$ on $\mathrm{Cu}(111)$ exhibits a substantial corrugation, whereas it was found that on more noble metals such as $\mathrm{Ag}$ the $\mathrm{ZnO}$ film is almost flat. On $\mathrm{Ag}(111)$, combined scanning tunnelling microscopy (STM) and surface $\mathrm{X}$ ray diffraction (SXRD) experiments have revealed that $\mathrm{ZnO}$ films transform to a more corrugated wurtzite like structure in the 3-4 monolayer (ML) range and that incomplete layers begin to form for thicknesses above 2 ML. ${ }^{19}$ DFT studies of such islands of $\mathrm{ZnO}$ in the 3-4 ML range on top of a closed $2 \mathrm{ML}$ film on $\mathrm{Ag}(111)$ showed that the islands undergo a structural transition to the wurtzite structure in the core of the island, whereas the edges and corners of the islands are characterized by reconstructions. ${ }^{24}$

In this contribution, we study the role of the underlying metal substrate for the chemical activity of ultrathin films of zinc oxide. Compared to our previous measurements carried out using a CuZn (brass) substrate, ${ }^{10}$ we here concentrate on $\mathrm{ZnO}$ grown on an $\mathrm{AgZn}$ substrate. The growth process is investigated as a function of the $\mathrm{O}_{2}$ exposure and the oxidation temperature by grazing emission $\mathrm{X}$ ray photoelectron spectros copy (XPS) and temperature dependent infrared reflectionabsorption spectroscopy (IRRAS) using $\mathrm{CO}$ as a probe molecule. The chemical activity of the formed $\mathrm{ZnO}$ films is probed by measuring the stretch frequency and binding energy of adsorbed $\mathrm{CO}^{25}$ We observe a different reactivity of the bilayer $\mathrm{ZnO}$ on $\mathrm{Ag}$ as evidenced by a much weaker $\mathrm{CO}$ adsorption and a blue shift of the $\mathrm{CO}$ vibrational frequency compared to $\mathrm{ZnO} / \mathrm{Cu}$. The results are interpreted in terms of the structure and electronic properties of $\mathrm{ZnO} / \mathrm{Ag}$ by comparison to DFT calculations.

\section{METHODS}

2.1. Experimental Methods. The IRRAS and XPS measurements were performed in an IR/XPS ultrahigh vacuum (UHV) apparatus, which combines a state of the art FTIR spectrometer (Bruker Vertex 80v) with a multichamber UHV system (Prevac). ${ }^{25}$ The $\mathrm{AgZn}(111)$ single crystal surface (Ag/ $\mathrm{Zn}$ ratio 9:1) was cleaned by cycles of $\mathrm{Ar}^{+}$sputtering $(1.5 \mathrm{kV}$, $10 \mathrm{~mA}, 1 \times 10^{-6} \mathrm{mbar}$ ) at room temperature, followed by annealing at $420 \mathrm{~K}$. Additionally, the cleanliness and oxidation states of the sample were monitored by XPS equipped with a VG Scienta R4000 electron energy analyzer. Exposure to CO at $65 \mathrm{~K}$ (cooling with liquid helium) was achieved by using a leak valve based directional doser connected to a tube $(2 \mathrm{~mm}$ in diameter) that terminated $3 \mathrm{~cm}$ from the sample surface and 50 $\mathrm{cm}$ from the hot cathode ionization gauge. IR data were accumulated by recording typically 1024 scans with a resolution of $4 \mathrm{~cm}^{-1}$. Prior to each exposure, a spectrum of a clean sample was recorded as a background reference.

The $\mathrm{ZnO}$ thin layers grown on the $\mathrm{AgZn}(111)$ substrate were prepared by oxidation of the clean $\operatorname{AgZn}(111)$ surface in $\mathrm{O}_{2}$ atmosphere $\left(1 \times 10^{-5} \mathrm{mbar}\right)$ at different temperatures for different periods of time. The thickness of the $\mathrm{ZnO}$ adlayers formed on the $\mathrm{Ag}$ substrate upon oxidation was determined based on the relative intensity of the $\mathrm{Zn} 2 \mathrm{p}_{3 / 2}$ and $\mathrm{Ag} 3 \mathrm{~d}_{5 / 2}$ XPS signals using the following expression: ${ }^{26}$

$$
\frac{I_{\mathrm{A}}}{I_{\mathrm{S}}}=\frac{T_{\mathrm{A}} \sigma_{\mathrm{A}} n_{\mathrm{A}} \lambda_{\mathrm{A}}\left(E_{\mathrm{A}}\right)}{T_{\mathrm{S}} \sigma_{\mathrm{S}} n_{\mathrm{S}} \lambda_{\mathrm{S}}\left(E_{\mathrm{S}}\right)} \cdot \frac{1-e^{-d / \lambda_{\mathrm{A}}\left(E_{\mathrm{A}}\right) \cdot \cos (\theta)}}{e^{-d / \lambda_{\mathrm{A}}\left(E_{\mathrm{S}}\right) \cdot \cos (\theta)}}
$$

Here, $I_{\mathrm{A}}$ and $I_{\mathrm{S}}$ denote the intensities of the adsorbate $(\mathrm{Zn})$ and substrate (Ag) XPS signals at a grazing angle $\theta=70^{\circ}, \sigma_{\mathrm{A}}$ and $\sigma_{\mathrm{S}}$ refer to the photoionization cross sections for $\mathrm{Zn} 2 \mathrm{p}_{3 / 2}$ (18.92) and $\mathrm{Ag} \mathrm{3d_{5/2 }}$ (10.66) (taken from ref 27). The mean free paths of the photoelectrons were calculated to amount to $\lambda_{\mathrm{A}}\left(E_{\mathrm{A}}\right)=$ $11.96 \AA, \lambda_{\mathrm{A}}\left(E_{\mathrm{S}}\right)=27.28 \AA$ and $\lambda_{\mathrm{S}}\left(E_{\mathrm{S}}\right)=15.2 \AA^{28,29} n_{\mathrm{A}}$ and $n_{\mathrm{S}}$ denote the atomic density of $\mathrm{ZnO}$ and $\mathrm{Ag}$ species. For $\mathrm{ZnO}$, two different structures were considered: wurzite $-4.89 \times 10^{-2}$ atoms $/ \AA^{3}$, graphitic $-4.08 \times 10^{-2}$ atoms $/ \AA^{3} .{ }^{15,30}$ For $\mathrm{Ag}, n_{S}=$ $5.89 \times 10^{-2}$ atoms $/ \AA^{3}$.

The binding energy of $\mathrm{CO}$ adsorbed to different sites was estimated based on temperature dependent IR experiments. IR spectra were recorded continually while heating the sample with a constant rate of $0.05 \mathrm{~K} / \mathrm{s}$. The normalized peak areas were shown as a function of temperature. The activation energies $\left(E_{\mathrm{d}}\right)$ for desorption of $\mathrm{CO}$ from the different sites were estimated via the Redhead equation ${ }^{31}$ assuming a pre exponential factor of $10^{13} \mathrm{~s}^{-1}$.

2.2. Theoretical Methods. The calculations were performed with the full potential, all electron simulation package $\mathrm{FHI}$ aims. ${ }^{32}$ Electronic exchange and correlation was treated using either the generalized gradient approximation (GGA) type Perdew-Burke-Ernzerhof (PBE) functional ${ }^{33}$ or the screened hybrid functional HSE0 $6^{34,35}$ together with the Tkatchenko-Scheffler (TS) semiempirical correction scheme for dispersion interactions. ${ }^{36}$ The TS parameters for $\mathrm{Ag}$ and $\mathrm{ZnO}$ were taken from ref 23 and account for surface and polarization effects. ${ }^{37,38}$ The PBE and HSE06 optimized lattice constants for $\mathrm{Ag}$, monolayer $\mathrm{ZnO}$ and bulk wurtzite $\mathrm{ZnO}$ were taken from ref 23 as well. Tight default settings were used for the basis set and integration grids. Test results using really tight settings for CO adsorption on the wurtzite (1010) surface showed that binding energies and frequencies were converged to within $1-2 \mathrm{meV}$ and $1-2 \mathrm{~cm}^{-1}$, respectively. The $\mathrm{ZnO} / \mathrm{Ag}$ system was modeled using the experimentally observed coincidence structure corresponding to a $(7 \times 7)$ graphitic bilayer $\mathrm{ZnO}$ film on a $(8 \times 8) \mathrm{Ag}(111)$ substrate $^{19}$ as in previous theoretical studies ${ }^{24,39}$ and a four layered metal slab (PBE calculations). The size of the $\mathrm{ZnO} / \mathrm{Ag}$ supercell was fixed by the PBE optimized lattice constant of $\mathrm{Ag}(4.15 \AA)$ and the $\mathrm{ZnO}$ lattice constant was adjusted accordingly, resulting in a $2 \%$ tensile strain in $\mathrm{ZnO}$ compared to the $\mathrm{PBE}$ optimized lattice constant of a free standing monolayer $\mathrm{ZnO}$ sheet (3.28 A). For the HSE06 calculations and due to the high computational cost of hybrid functional calculations, we instead modeled the $\mathrm{ZnO} / \mathrm{Ag}$ system using a $(2 \times 2)$ graphitic bilayer $\mathrm{ZnO}$ film on a $(2 \times 2) \mathrm{Ag}(111)$ substrate. In these calculations, we instead released the strain in the lateral directions on $\mathrm{Ag}$, resulting in a tensile strain of $\sim 11 \%$. The Ag slab contained two layers with an interlayer distance that had been relaxed to compensate for the strain in the lateral directions. The $\mathrm{ZnO}$ film was kept fixed in a flat geometry with interlayer distances corresponding to the mean distances obtained with $\mathrm{PBE}$ in the $(7 \times 7) \mathrm{ZnO} /(8 \times 8) \mathrm{Ag}$ calculation. Bulk wurtzite $\mathrm{ZnO}$ with the (1010) surface termination was modeled using four $\mathrm{ZnO}$ 
layers and a $(2 \times 1)$ cell. This cell contains four $\mathrm{Zn}$ atoms at two inequivalent heights in the top layer and is thus comparable in lateral size to a $(2 \times 2)$ cell for $\mathrm{ZnO}$ in the flat graphitic structure.

For the $(7 \times 7) \mathrm{ZnO} /(8 \times 8) \mathrm{Ag}$ calculation the Brillouin zone was sampled using a $(2 \times 2) k$ point grid. For the remaining smaller structures a $(4 \times 4) k$ point grid was used. Denser $k$ point grids were used for the density of states calculations. A vacuum region of $30 \AA$ perpendicular to the surface separated the slabs from their periodic images and a dipole correction was applied. ${ }^{40}$ For the $(7 \times 7) \mathrm{ZnO} /(8 \times 8)$ $\mathrm{Ag}$ and $\mathrm{ZnO}(1010)$ calculations the two bottom layers were kept fixed in their bulk truncated positions, while the top layers and adsorbed $\mathrm{CO}$ were relaxed until the maximum force in the system fell below $0.01 \mathrm{eV} / \AA \AA$. For the $(2 \times 2) \mathrm{ZnO} /(2 \times 2) \mathrm{Ag}$ calculations, only the adsorbed $\mathrm{CO}$ molecule was relaxed. The (harmonic) vibrational frequency of the $\mathrm{CO}$ stretching mode was calculated using a finite difference scheme.

\section{RESULTS AND DISCUSSION}

3.1. XPS Data. The growth of thin $\mathrm{ZnO}$ adlayers was monitored by highly surface sensitive grazing emission XPS and Auger electron spectroscopy (AES). The XPS and AES data in Figure 1 and Figure S1 reveal that the clean $\operatorname{AgZn(111)~alloy~}$
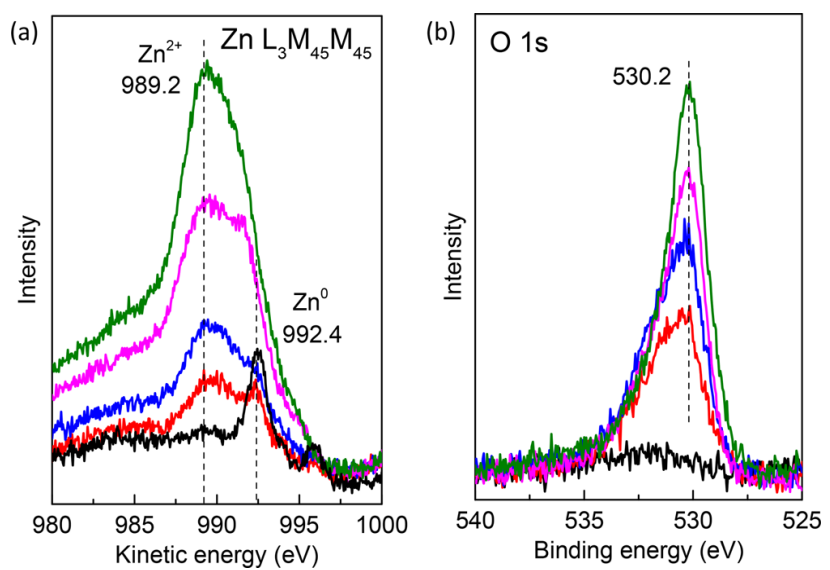

Figure 1. Grazing emission (a) $\mathrm{Zn} \mathrm{L}_{3} \mathrm{M}_{45} \mathrm{M}_{45}$ Auger spectra and (b) O 1s spectra recorded before (black curve) and after oxidation of the $\mathrm{AgZn}(111)$ sample with $\mathrm{O}_{2}\left(1 \times 10^{-5} \mathrm{mbar}\right.$ for $\left.10 \mathrm{~min}\right)$ at $300 \mathrm{~K}$ (red curve), $420 \mathrm{~K}$ (blue curve), $500 \mathrm{~K}$ (magenta curve), and $600 \mathrm{~K}$ (olive curve).

surface is dominated by $\mathrm{Ag}$ species. The $\mathrm{Zn} \mathrm{L}_{3} \mathrm{M}_{45} \mathrm{M}_{45}$ Auger spectra are sensitive to the oxidation state of zinc and show large changes in the line shape with an energy difference of about $4 \mathrm{eV}$ between $\mathrm{Zn}^{2+}$ and metallic $\mathrm{Zn}^{0}{ }^{41,42}$ However, a clear chemical shift is not observed in the $\mathrm{Zn} 2 \mathrm{p}$ core level spectra (see Figures S2 and S3) due to screening effects in the final core-hole state. ${ }^{42}$ The weak $\mathrm{Zn} \mathrm{L}_{3} \mathrm{M}_{45} \mathrm{M}_{45}$ Auger peak at $992.4 \mathrm{eV}$ (kinetic energy, KE) demonstrates the presence of a very small portion of metallic $\mathrm{Zn}$ component $(\sim 2 \%)$ at the surface, which is substantially lower than the nominal concentration of $\mathrm{Zn}$ in the bulk (10\%) of the sample. Exposure of the $\operatorname{AgZn}(111)$ substrate to molecular oxygen at room temperature leads to the formation of surface $\mathrm{ZnO}$ species, as confirmed by the appearance of the typical $\mathrm{Zn}^{2+} \mathrm{L}_{3} \mathrm{M}_{45} \mathrm{M}_{45}$ peak at $989.2 \mathrm{eV}(\mathrm{KE})$ and the $\mathrm{O} 1 \mathrm{~s}$ peak at $530.2 \mathrm{eV}$. Note that the oxidized zinc species is characterized by a much broader and asymmetric (at the higher BE side) line shape as compared to metallic $\mathrm{Zn} .{ }^{41}$ Upon further oxidation at elevated temperatures, the $\mathrm{Zn}^{2+}$ and $\mathrm{O}^{2-}$ related XPS signals increase gradually in intensity, indicating a pronounced increase of the surface $\mathrm{Zn}$ concentration (Figure 1).

On the basis of a quantitative analysis of the intensity ratio between $\mathrm{Zn} 2 \mathrm{p}_{3 / 2}$ and $\mathrm{Ag} 3 \mathrm{~d}_{5 / 2}$ XPS data (Figures S2 and S3), the average thickness of the thin $\mathrm{ZnO}$ adlayer can be estimated. This yields a value of about $1.9 \AA$ (assuming graphitic type $\mathrm{ZnO})$ after oxidation of the AgZn substrate with $\mathrm{O}_{2}\left(1 \times 10^{-5}\right.$ mbar) at $600 \mathrm{~K}$ for $10 \mathrm{~min}$, corresponding to the presence of 1 $\mathrm{ML}$ of $\mathrm{ZnO}$. Prolonged oxidation for $20 \mathrm{~min}$ leads to the formation of a $\mathrm{ZnO}$ bilayer ( $3.4 \AA$ for planar $\mathrm{ZnO}$ ). Exposure of the sample to $\mathrm{O}_{2}$ at $600 \mathrm{~K}$ for $40 \mathrm{~min}$ results in a further growth of $\mathrm{ZnO}$ films with an average thickness of about $4.4 \AA$ (assuming graphitic type $\mathrm{ZnO}$ ) or $3.7 \AA$ (assuming wurztite type $\mathrm{ZnO})$.

3.2. IRRAS Data. Pristine and oxidized AgZn(111) surfaces were further characterized by IRRAS using $\mathrm{CO}$ as a probe molecule (see Figure 2). After CO adsorption on the oxygen

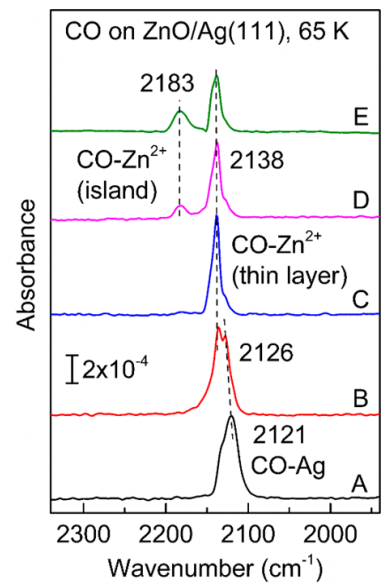

Figure 2. IRRAS data recorded after $1 \mathrm{~L}$ CO adsorption on the pristine and oxidized $\mathrm{AgZn}(111)$ surfaces at $65 \mathrm{~K}$. The $\mathrm{ZnO}$ adlayers were prepared by oxidizing the (A) $\mathrm{AgZn}(111)$ surface in $1 \times 10^{-5}$ mbar $\mathrm{O}_{2}$ atmosphere at $500 \mathrm{~K}$ for (B) $10 \mathrm{~min}$, and at $600 \mathrm{~K}$ for (C) 10 min, (D) $20 \mathrm{~min}$, (E) $40 \mathrm{~min}$.

free $\operatorname{AgZn}(111)$ surface at $65 \mathrm{~K}$, a predominant IR band was observed at $2121 \mathrm{~cm}^{-1}$ (see Figure $2 \mathrm{~A}$ ), which is assigned to $\mathrm{CO}$ bound to $\mathrm{Ag}$ sites. This band disappears upon slightly heating to $70 \mathrm{~K}$, indicating a rather weak interaction between $\mathrm{CO}$ and Ag. This finding is in good agreement with the results of $\mathrm{CO}$ adsorption on $\operatorname{Ag}(111)$ reported by Jacobi and co workers. ${ }^{43}$ They found that $\mathrm{CO}$ is weakly bound to $\mathrm{Ag}$ sites (physisorption) with a random orientation of the molecular axis in the monolayer.

Oxidation at $500 \mathrm{~K}$ leads to the appearance of a second IR band at $2136 \mathrm{~cm}^{-1}$ (Figure 2B), while the intensity of the $\mathrm{Ag}$ bonded $\mathrm{CO}$ band decreases, accompanied by a slight blue shift to $2126 \mathrm{~cm}^{-1}$. After further exposure to oxygen at $600 \mathrm{~K}$ for 10 min, only one single, sharp CO peak at $2138 \mathrm{~cm}^{-1}$ is detected, whereas the Ag related IR band disappears completely (Figure 2C). Our IRRAS data, together with the XPS/AES results discussed in section 3.1, provide solid evidence for the formation of a closed monolayer of $\mathrm{ZnO}$ after this oxidation treatment. Furthermore, the IR spectrum remains nearly unchanged for $\mathrm{ZnO}$ films with a thickness of $0.34 \mathrm{~nm}$ 
(corresponding to a $\mathrm{ZnO}$ bilayer, see Figure 2D). Therefore, we conclude that the $2138 \mathrm{~cm}^{-1}$ band is characteristic for CO species adsorbed to $\mathrm{Zn}^{2+}$ sites on the surface of $\mathrm{ZnO}$ thin layers. It should be noted that other approaches (e.g., $\mathrm{Zn}$ deposition in oxygen atmosphere) typically result in not closed $\mathrm{ZnO}$ thin films.

More extended oxidation at $600 \mathrm{~K}$ for prolonged time leads to the appearance of a weak high frequency $\mathrm{CO}$ vibration at $2183 \mathrm{~cm}^{-1}$, which becomes more pronounced at $\mathrm{ZnO}$ coverages higher than $2 \mathrm{ML}$ (see Figure 2E). Simultaneously, the $2138 \mathrm{~cm}^{-1}$ band decreases in intensity. These observations suggest the coexistence of a thin $\mathrm{ZnO}$ bilayer and thicker $\mathrm{ZnO}$ clusters (islands). The IR band at $2183 \mathrm{~cm}^{-1}$ is in good agreement in frequency with those reported for $\mathrm{CO}$ adsorption on $\mathrm{ZnO}$ single crystal surfaces. ${ }^{44-46}$ The substantial blue shift $\left(40 \mathrm{~cm}^{-1}\right.$ ) compared to the gas phase value indicates that the interaction between $\mathrm{CO}$ and the thicker $\mathrm{ZnO}$ islands is dominated by the electrostatic interaction (Stark effect and Pauli repulsion $)^{47}$ and possibly electron donation from the $\mathrm{CO}$ $5 \sigma$ orbital to the surface $\mathrm{Zn}$ cations (see also theoretical analysis in Sect. 3.4), in accord with $\mathrm{CO}$ adsorption on wurtzite type $\mathrm{ZnO}$ substrates. ${ }^{25}$ These findings reveal that wurtzite type $\mathrm{ZnO}$ islands are formed for thickness above $2 \mathrm{ML}$ on $\mathrm{Ag}(111)$, in line with the STM and SXRD observations. ${ }^{19}$

The temperature dependent IRRAS experiments (see Figure 3) provide insight into the thermal stability of various $\mathrm{CO}$
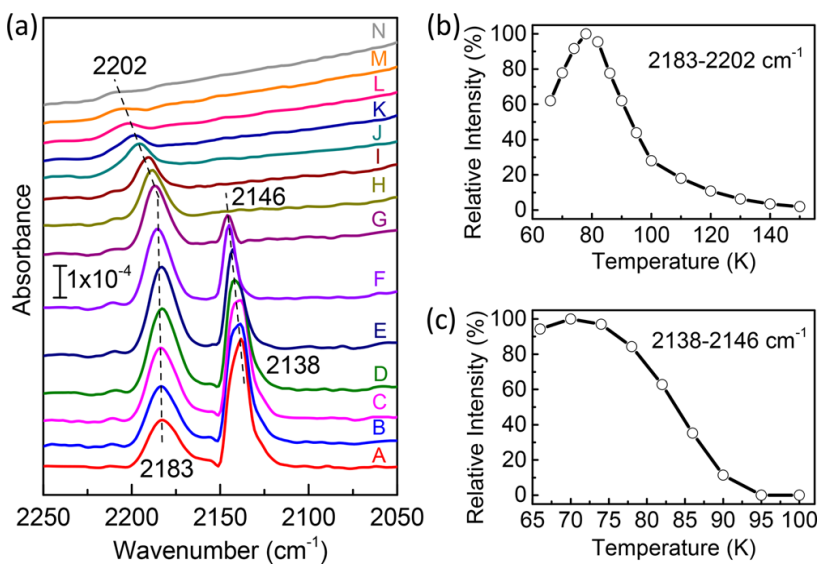

Figure 3. (a) IRRAS spectra recorded after exposing the thin $\mathrm{ZnO}$ adlayers to $1 \mathrm{~L} \mathrm{CO}$ at $(\mathrm{A}) 66 \mathrm{~K}$ and then heating gradually to higher temperatures: (B) $70 \mathrm{~K},(\mathrm{C}) 74 \mathrm{~K}$, (D) $78 \mathrm{~K},(\mathrm{E}) 82 \mathrm{~K}$, (F) $86 \mathrm{~K},(\mathrm{G})$ $90 \mathrm{~K},(\mathrm{H}) 95 \mathrm{~K},(\mathrm{I}) 100 \mathrm{~K},(\mathrm{~J}) 110 \mathrm{~K},(\mathrm{~K}) 120 \mathrm{~K},(\mathrm{~L}) 130 \mathrm{~K},(\mathrm{M}) 140$ $\mathrm{K},(\mathrm{N}) 150 \mathrm{~K}$. (b) Normalized intensity of the high frequency band as a function of sample temperature. (c) Normalized intensity of the low frequency band as a function of sample temperature.

species. Interestingly, the intensity of both $\mathrm{CO}$ bands increases first upon heating to about $75 \mathrm{~K}$. This is attributed to a restructuring process of the $\mathrm{CO}$ adlayer from a nonuniform, disordered distribution at low temperatures $(66 \mathrm{~K})$ to a more ordered structure, as observed for $\mathrm{CO}$ adsorption on ceria surfaces. ${ }^{48}$ Further raising the temperature leads to a gradual attenuation of both $\mathrm{CO}$ signals due to thermal induced desorption. Based on a quantitative analysis of the IR data (see Figure 3b,c) and assuming a pre exponential factor of $10^{13}$ $\mathrm{s}^{-1}$, the binding energies were determined to amount to 0.30 $\mathrm{eV}(29 \mathrm{~kJ} / \mathrm{mol})$ for $\mathrm{CO}$ adsorbed to wurtzite type $\mathrm{ZnO}$ clusters (islands) and $0.24 \mathrm{eV}(23 \mathrm{~kJ} / \mathrm{mol})$ for $\mathrm{ZnO}$ bilayer bonded $\mathrm{CO}$ species, respectively. The binding energy of $0.30 \mathrm{eV}$ is consistent with those determined for $\mathrm{CO}$ bound to $\mathrm{Zn}^{2+}$ sites on $\mathrm{ZnO}(1010)(0.32 \mathrm{eV})$ and $\mathrm{Zn} \mathrm{ZnO}(0001)(0.28 \mathrm{eV})$ surfaces. ${ }^{44-46}$ These results reveal that $\mathrm{CO}$ is more weakly bound to bilayer $\mathrm{ZnO}$ formed on $\mathrm{Ag}(111)$ compared to thicker wurtzite type $\mathrm{ZnO}$ islands, which is in contrast to the observation of a significantly enhanced interaction of $\mathrm{CO}$ with ultrathin $\mathrm{ZnO}$ films on $\mathrm{Cu}(111) .{ }^{10}$ The present IRRAS data provide direct evidence that the metal substrate plays a crucial role in the chemical properties of the ultrathin $\mathrm{ZnO}$ films.

Importantly, we found a clear blue shift for both $\mathrm{CO}$ species with annealing to higher temperatures (see Figure 3a), i.e., with decreasing $\mathrm{CO}$ coverage. At very low coverage $(\theta \rightarrow 0$, isolated $\mathrm{CO}$ adsorbates), the IR bands are located at $2146 \mathrm{~cm}^{-1}$ for $\mathrm{CO}$ adsorbed on the $\mathrm{ZnO}$ bilayer surface and at $2202 \mathrm{~cm}^{-1}$ for $\mathrm{CO}$ on wurtzite type $\mathrm{ZnO}$ islands. This coverage induced frequency shift is attributed to lateral adsorbate-adsorbate interactions including both dynamic (dipole-dipole coupling) and substrate mediated static effects (for details, please see refs 25 and 44).

3.3. DFT Results. To support the assignment of the IRRAS bands, we carried out DFT calculations of $\mathrm{CO}$ adsorption energies and vibrational frequencies. The use of GGA type DFT functionals for adsorption on $\mathrm{ZnO}$ is in general not uncritical due to the well known issues with describing the electronic structure of oxides at the GGA level of theory. A hybrid functional like the HSE06, on the other hand, can generally be expected to perform better, since it improves on the self interaction error in DFT by incorporating a portion of Hartree-Fock exact exchange. To illustrate this we compare data for CO adsorption on the wurtzite (1010) surface obtained at the PBE and HSE06 levels of theory (see Table 1). The $\mathrm{CO}$ molecule adsorbs to a $\mathrm{Zn}$ atom in a tilted geometry, which is rotated about 25 degrees from the surface normal (see Figure 4a). While both functionals give very similar values for the structural data (tilt angle, binding distance) and the adsorption energy $(0.45 \mathrm{eV}$ with $\mathrm{PBE}$ and $0.47 \mathrm{eV}$ with HSE06) in reasonable agreement with available experimental measurements $\left(0.32 \mathrm{eV}^{46}\right)$, the vibrational frequencies come out very different. The HSE06 functional correctly reproduces the blue shift of around $40 \mathrm{~cm}^{-1}$ with respect to the gas phase frequency that is found experimentally, ${ }^{44}$ while the $\mathrm{PBE}$ functional gives a shift around zero. A similar improvement of performance as regards vibrational shifts by using a hybrid functional (PBE0) was recently reported by Tosoni et al. ${ }^{39}$

As mentioned in the previous section, we expect that the high frequency band shifted around $40 \mathrm{~cm}^{-1}$ with respect to the gas phase, which is measured after prolonged oxidation, results from $\mathrm{CO}$ adsorbed to thick $\mathrm{ZnO}$ films. A recent DFT study on the structure of $\mathrm{ZnO}$ islands in the 3-4 ML range on top of the closed $2 \mathrm{ML}$ film suggested that such islands will undergo a structural transition to a wurtzite like phase. ${ }^{24}$ The present HSE06 result of a shift of around $40 \mathrm{~cm}^{-1}$ for the wurtzite structure is therefore in excellent agreement with the measured high frequency band at $2183 \mathrm{~cm}^{-1}$ observed after the saturation of $\mathrm{CO}$ adsorption (curve $\mathrm{A}$ in Figure 3a). Due to the high computational cost of hybrid functional calculations, the present result was calculated for a rather high $\mathrm{CO}$ coverage of 0.5 ML. However, as discussed in ref 39, the shift (both at the GGA and hybrid functional level) tends to become more positive for lower coverages. This effect is in good agreement with the shift to higher frequencies observed after annealing, i.e., gradually decreasing $\mathrm{CO}$ coverage (curves $\mathrm{E}-\mathrm{N}$ in Figure 3a). 
Table 1. Calculated and Experimental CO Adsorption Energies $E_{\mathrm{CO}}$ (in eV), Zn-C Binding Distances $d_{\mathrm{Zn}-\mathrm{C}}($ in $\AA$ ), Tilt of the CO Molecule with Respect to the Surface Normal $\alpha$ (in deg.), Shift of the C-O Binding Distance with Respect to the Gas Phase Value (1.135 $\AA$ with PBE and 1.122 $\AA$ with HSE06) $\Delta d_{\mathrm{C}-\mathrm{O}}$ (in $\AA$ ), and Shift of the CO Vibrational Frequency with Respect to the Gas Phase Value $\left(2128 \mathrm{~cm}^{-1}\right.$ with PBE and $2238 \mathrm{~cm}^{-1}$ with HSE06) $\Delta v_{\mathrm{CO}}\left(\right.$ in $\left.\mathrm{cm}^{-1}\right)$

\begin{tabular}{|c|c|c|c|c|c|c|}
\hline system & method & $E_{\mathrm{CO}}$ & $d_{\mathrm{Zn}-\mathrm{C}}$ & $\alpha$ & $\Delta d_{\mathrm{C}-\mathrm{O}}$ & $\Delta v_{\mathrm{CO}}$ \\
\hline \multirow[t]{5}{*}{$\mathrm{ZnO}(10 \overline{1} 0)$} & PBE+TS & 0.45 & 2.19 & 25 & 0.001 & +7 \\
\hline & HSE06+TS & 0.47 & 2.23 & 28 & 0.004 & +37 \\
\hline & $\mathrm{PBE}+\mathrm{U}+\mathrm{D} 2^{\prime b}$ & & 2.16 & 40 & $\sim 0$ & 5 \\
\hline & $\mathrm{PBE} 0+\mathrm{D} 2^{a, b}$ & 0.57 & 2.13 & 35 & 0.004 & +41 \\
\hline & exp. & $0.32^{c}$ & & & & $+42^{d}$ \\
\hline \multirow[t]{4}{*}{$(7 \times 7) \mathrm{ZnO} /(8 \times 8) \mathrm{Ag}$} & PBE+TS: Site I & 0.36 & 2.27 & 38 & 0.002 & +5 \\
\hline & PBE+TS: Site II & 0.24 & 2.33 & 41 & 0.001 & 3 \\
\hline & $\mathrm{PBE}+\mathrm{U}+\mathrm{D} 2^{\prime b}$ & 0.24 & 2.24 & 9 & 0.003 & +6 \\
\hline & exp. & 0.24 & & & & +3 \\
\hline \multirow[t]{2}{*}{$(2 \times 2) \mathrm{ZnO} /(2 \times 2) \mathrm{Ag}$} & $\mathrm{PBE}+\mathrm{TS}$ & 0.13 & 2.85 & 61 & +0.001 & 16 \\
\hline & HSE06+TS & 0.12 & 2.88 & 56 & $\sim 0$ & 5 \\
\hline
\end{tabular}

${ }^{a}$ Obtained in a $(3 \times 2)$ cell using eight $\mathrm{ZnO}$ layers. ${ }^{b}$ From ref $39 .{ }^{c}$ From ref $46 .{ }^{d}$ From ref 44.

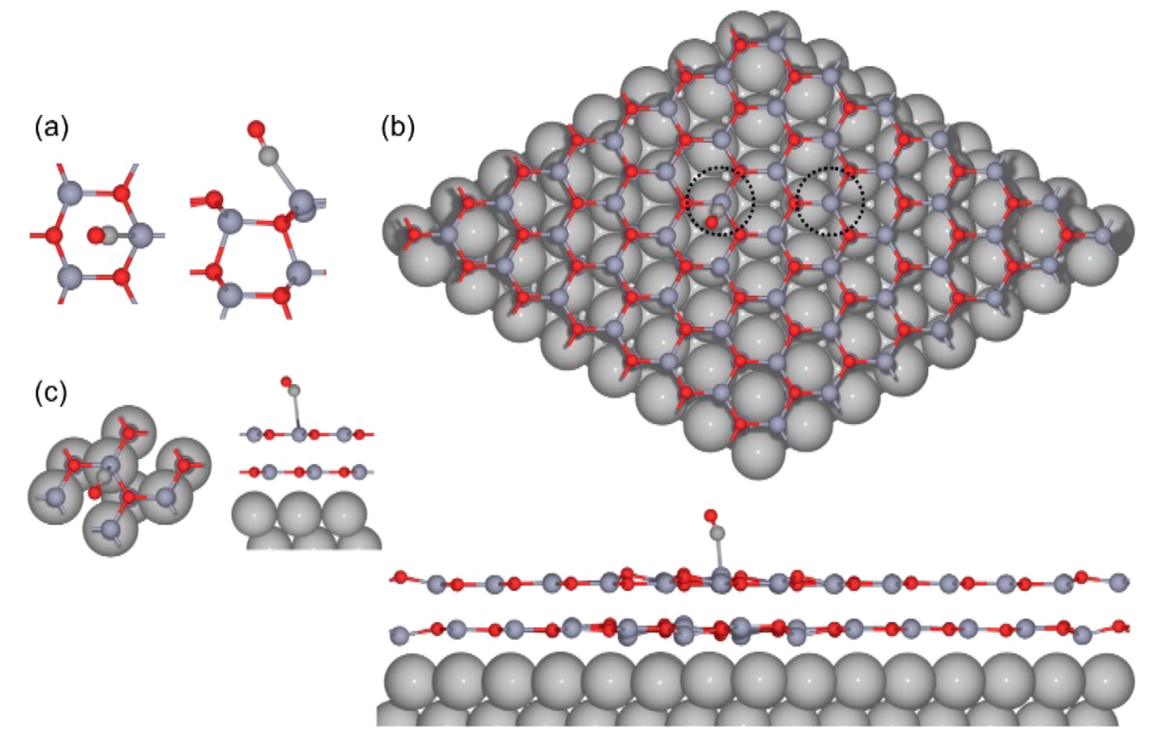

Figure 4. DFT optimized structures (top and side view) of CO adsorbed on (a) the wurtzite (1010) surface, (b) the large $(7 \times 7) \mathrm{ZnO} /(8 \times 8) \mathrm{Ag}$ structure and $(\mathrm{c})$ the smaller $(2 \times 2) \mathrm{ZnO} /(2 \times 2) \mathrm{Ag}$ structure. For clarity, the bonds between the flat graphitic $\mathrm{ZnO}$ layers have been omitted. In panel $b$, the dashed black circles highlight adsorption site I (shown structure) and II (empty circle).

Before analyzing further the problematic description of $\mathrm{CO}$ adsorption on $\mathrm{ZnO}$ at the GGA level, we present also the results for the bilayer $\mathrm{ZnO} / \mathrm{Ag}$ system. In Table 1 we report PBE data for two different adsorption sites I and II within the Moire supercell of the full $(7 \times 7) \mathrm{ZnO} /(8 \times 8) \mathrm{Ag}$ structure (see Figure $4 \mathrm{~b}$ ). At site I CO binds the strongest with $0.36 \mathrm{eV}$, whereas at site II the binding is reduced to $0.24 \mathrm{eV}$. Given that $\mathrm{CO}$ is dosed at very low temperatures in the present experimental work, we expect several site types within the Moire supercell to be populated. The derived experimental binding energy of $0.24 \mathrm{eV}$ corresponds then rather well with the calculated values, assuming that the experiment likely measures the average binding energy for several different sites. The $\mathrm{CO}$ binding energy on $\mathrm{ZnO} / \mathrm{Ag}$ is thus much lower than the binding energy obtained at the wurtzite surface in the present work ( $0.45 \mathrm{eV}$ using $\mathrm{PBE})$ and the previously reported binding energy of $0.52 \mathrm{eV}$ for $\mathrm{ZnO} / \mathrm{Cu}$ (also $\mathrm{PBE}),{ }^{10}$ indicating that the $\mathrm{CO}$ molecule is only bound by weak dispersive interactions on $\mathrm{ZnO} / \mathrm{Ag}$. This different behavior is attributed to the flat geometry of the $\mathrm{ZnO}$ bilayer adsorbed on an $\mathrm{Ag}(111)$ surface (see Figure 4b) as compared to the buckled structure of $\mathrm{ZnO}$ in the wurtzite structure (see Figure $4 \mathrm{a}$ ) and the previously identified rumpling of the $\mathrm{ZnO}$ bilayer on a $\mathrm{Cu}(111)$ surface. ${ }^{10}$ For the vibrational frequency, we obtain a slight blue shift of $5 \mathrm{~cm}^{-1}$ (site I) and a slight red shift of 3 $\mathrm{cm}^{-1}$ (site II) for $\mathrm{ZnO} / \mathrm{Ag}$ using PBE. These values correspond well with the measured low frequency band at low coverage (see curve $\mathrm{G}$ in Figure 3a), which is blue shifted by $3 \mathrm{~cm}^{-1}$ with respect to gas phase $\mathrm{CO}$. Our results are also in good agreement with recent results reported by Tosoni et al. (0.24 $\mathrm{eV}$ binding energy, frequency blue shifted by $\left.6 \mathrm{~cm}^{-1}\right){ }^{39}$

The question that remains, in light of the above described failure of PBE to describe the frequency shift for the wurtzite (1010) surface, is whether the good agreement with experiment obtained at the PBE level of theory for the $\mathrm{ZnO} / \mathrm{Ag}$ system is real or results from a fortuitous cancellation of errors. To answer this question, we proceed to a direct comparison of $\mathrm{PBE}$ and HSE06 for the $\mathrm{ZnO} / \mathrm{Ag}$ system. Due to the high computational cost of hybrid functional calculations, we are presently not able to consider the full $(7 \times 7) \mathrm{ZnO} /(8 \times 8) \mathrm{Ag}$ 

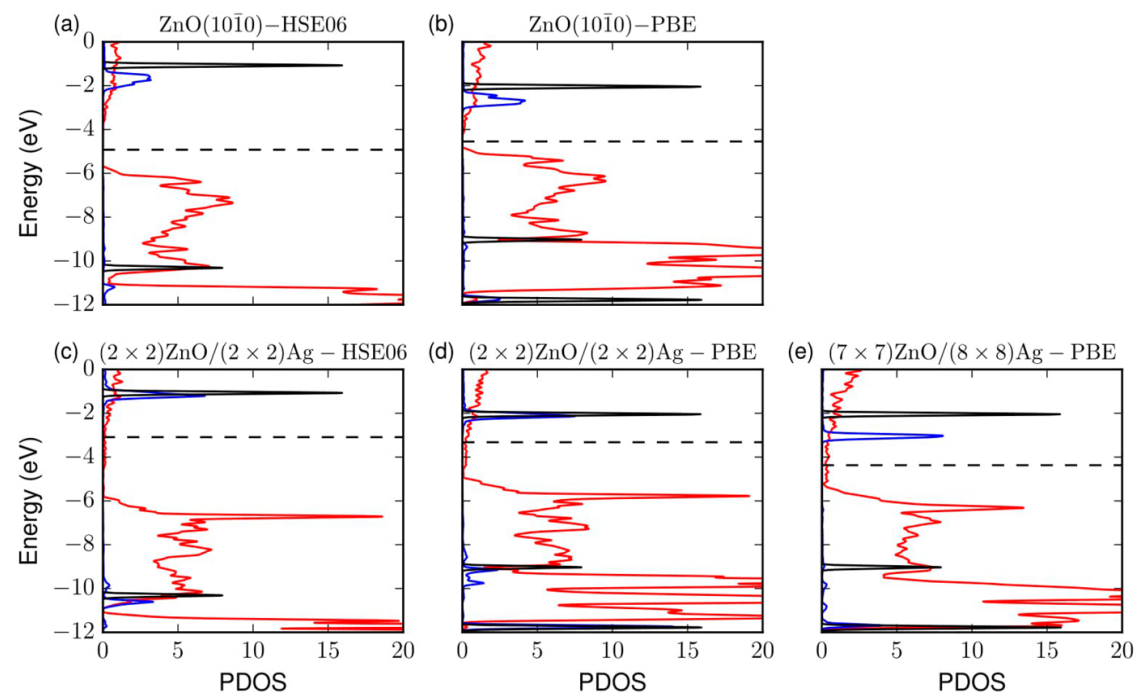

Figure 5. DFT projected density of states (PDOS) for CO adsorbed to various surfaces calculated using either PBE or HSE06. Red curves are projected onto $\mathrm{ZnO}$, blue curves are projected onto the $\mathrm{CO}$ molecule, and the levels of the isolated $\mathrm{CO}$ molecule are superimposed in black. The Fermi level is marked with a dashed line. (a) $\mathrm{ZnO}(1010) \mathrm{HSE06}$, (b) $\mathrm{ZnO}(1010) \mathrm{PBE},(\mathrm{c})(2 \times 2) \mathrm{ZnO} /(2 \times 2) \mathrm{Ag} \mathrm{HSE06},(\mathrm{d})(2 \times 2) \mathrm{ZnO} /(2 \times$ 2) $\mathrm{Ag} \mathrm{PBE}$, and $(\mathrm{e})(7 \times 7) \mathrm{ZnO} /(8 \times 8) \mathrm{Ag} \mathrm{PBE}$.

structure at the HSE06 level of theory. Instead, we consider a smaller $(2 \times 2) \mathrm{ZnO} /(2 \times 2) \mathrm{Ag}$ structure where the residual strain is released on the $\mathrm{Ag}$ and the bilayer $\mathrm{ZnO}$ film is kept fixed in a flat geometry as described in Section 2.2 (see Figure 4c). The $\mathrm{CO}$ adsorption energies calculated with PBE and HSE06 for this structure are around $0.13 \mathrm{eV}$ (see Table 1). The reduced binding, which is also reflected in the enlarged $\mathrm{Zn}-\mathrm{C}$ binding distance of around $2.8 \AA$ (as compared to around $2.2 \AA$ for the other systems considered), is likely a consequence of the fixed, flat geometry of the $\mathrm{ZnO}$ film. Interestingly, the vibrational frequencies also come out very similar at the $\mathrm{PBE}$ and HSE06 levels of theory, with the PBE frequency being only slightly $\left(\sim 10 \mathrm{~cm}^{-1}\right)$ more red shifted than the HSE06 frequency. Comparing on the other hand the frequencies calculated with $\mathrm{PBE}$ for the large and small $\mathrm{ZnO} / \mathrm{Ag}$ supercells, it is seen that the small system is $\sim 20 \mathrm{~cm}^{-1}$ more red shifted than the large system. The difference between the large and the small supercells should be mainly of electrostatic origin resulting from the difference in work function of the strained two layer versus unstrained four layer Ag slabs, the slightly larger buckling of $\mathrm{ZnO}$ in the large supercell and the enlarged distance of the $\mathrm{CO}$ from the surface in the small supercell. Assuming that the effect of these changes is well described using $\mathrm{PBE}$, we can estimate a hybrid vibrational shift for the large supercell by adding the difference between the HSE06 and PBE frequencies for the small supercell $\left(\sim 10 \mathrm{~cm}^{-1}\right)$ to the PBE shift for the large supercell, resulting in an effective HSE06 blue shift of $\sim 10 \mathrm{~cm}^{-1}$. This value is still consistent with the experimental measurement. Therefore, based on the good agreement between PBE and HSE06 for the small $\mathrm{ZnO} / \mathrm{Ag}$ supercell and the similarity of the small and large supercells, we expect that the good agreement with experiment obtained with PBE for the large supercell is trustworthy.

3.4. Analysis and Discussion of DFT Results. As discussed in ref 25 , the vibrational frequency shift of $\mathrm{CO}$ on $\mathrm{ZnO}$ surfaces is generally explained via two mechanisms: (i) the electrostatic interaction with the electric field of the surface metal cations (Stark effect) and (ii) electron donation and back donation to the $\mathrm{CO}$ frontier orbitals (Blyholder model ${ }^{49}$ ).
The former effect polarizes the $\mathrm{CO}$ molecule and strengthens the internal bond, which leads to a shortening of the bond and a blue shifted frequency. The latter effect can lead to either a blue shift in case electrons are donated from the $5 \sigma$ highest occupied molecular orbital (HOMO) to the surface or a red shift in case electrons are back donated from the surface into the $2 \pi^{*}$ lowest unoccupied molecular orbital (LUMO).

In order to further investigate which of these mechanisms are at play in the various systems, we plot in Figure 5 the projected density of states onto $\mathrm{ZnO}$ (red curves) and onto the $\mathrm{CO}$ molecule (blue curves). The levels of the isolated CO molecule are in each case superimposed in black. We begin by comparing $\mathrm{CO}$ on $\mathrm{ZnO}(1010)$ calculated with HSE06 (Figure 5a) and PBE (Figure $5 \mathrm{~b}$ ). As expected, the use of a hybrid functional (HSE06) corrects for the GGA level underestimation of the $\mathrm{ZnO}$ band gap and HOMO-LUMO gap of the isolated $\mathrm{CO}$ molecule. The Fermi level is influenced by the position of the valence band maximum (VBM) and therefore shifts from -4.55 $\mathrm{eV}$ with PBE to $-4.92 \mathrm{eV}$ with HSE06 relative to the vacuum level. This increase in the work function for HSE06 leads to a larger electric field at the surface, which is expected to give a larger blue shift of the $\mathrm{CO}$ vibrational frequency. Considering now the HOMO and LUMO levels, we note that the interaction of the $\mathrm{CO}$ molecule with the surface leads to a significant down shift and broadening of the LUMO level, which brings it close to the Fermi level. In that context it is worth noting that the observed tilted adsorption geometry of the CO molecule favors the hybridization of the LUMO level with the surface states since it is of $\pi$ symmetry. The HOMO level also shows a large degree of hybridization; however, since it is located rather far away from the Fermi level, we expect that back donation into the LUMO level will play the largest role in the Blyholder model. Using PBE, we calculate a vibrational shift close to zero. We therefore tentatively suggest that the two opposite effects are at play, blue shift from the Stark effect and red shift from back donation into the $2 \pi^{*}$ orbital, largely cancel each other. With the HSE06 functional, on the other hand, we expect the blue shift to dominate as a consequence of the increased work function and the increased distance between the 
LUMO level and the Fermi level. Indeed, only the HSE06 functional is observed to correctly reproduce the $40 \mathrm{~cm}^{-1}$ blue shift observed experimentally.

Next, we turn to the comparison of HSE06 and PBE for the $(2 \times 2) \mathrm{ZnO} /(2 \times 2) \mathrm{Ag}$ structure. As for the $\mathrm{ZnO}(1010)$ surface, we observe a larger $\mathrm{ZnO}$ band gap with the hybrid functional. However, as a consequence of $n$ type doping from the metal surface, the Fermi level now moves up in the conduction band and both functionals give a very similar (reduced) value for the work function $(3.32 \mathrm{eV}$ with $\mathrm{PBE}$ and $3.10 \mathrm{eV}$ with HSE06). We therefore expect also a similar blue shift from the Stark effect for the two functionals. Compared to $\mathrm{ZnO}(1010)$, it is seen that the LUMO level interacts much less with the surface for $(2 \times 2) \mathrm{ZnO} /(2 \times 2) \mathrm{Ag}$, which is related to the much weaker binding of $\mathrm{CO}$ to $\mathrm{ZnO} / \mathrm{Ag}$ in general and to $\mathrm{ZnO} / \mathrm{Ag}$ in the smaller, constrained structure in particular (as evidenced by the lower binding energies and enlarged binding distances, see Table 1). The amount of red shifting of the CO vibrational frequency is expected to be dependent both on how close the LUMO level is to the Fermi level and how strongly it hybridizes. For HSE06, the LUMO level is located slightly further away from the Fermi level and we therefore expect the HSE06 frequency to be blue shifted with respect to PBE, which is indeed the case (by $\sim 10 \mathrm{~cm}^{-1}$ ). The rather small difference between the HSE06 and PBE results is likely a consequence of the very small degree of hybridization in this system.

Finally, we compare the $(7 \times 7) \mathrm{ZnO} /(8 \times 8) \mathrm{Ag}($ site I) and $(2 \times 2) \mathrm{ZnO} /(2 \times 2) \mathrm{Ag}$ structures at the PBE level of theory. It is seen that the degree of hybridization of the LUMO level and its distance to the Fermi level are very similar in the two systems. The most notable change is a decrease in the work function to $3.32 \mathrm{eV}$ for the $(2 \times 2) \mathrm{ZnO} /(2 \times 2) \mathrm{Ag}$ structure compared to $4.37 \mathrm{eV}$ for the $(7 \times 7) \mathrm{ZnO} /(8 \times 8) \mathrm{Ag}$ system, which likely derives from the fixed geometry of the $\mathrm{ZnO}$ film and the strain in the $\mathrm{Ag}$ slab in the former system. As a consequence, we would expect the $\mathrm{CO}$ frequency to be more blue shifted in the $(7 \times 7) \mathrm{ZnO} /(8 \times 8) \mathrm{Ag}$ system, which is indeed the case (by $\sim 20 \mathrm{~cm}^{-1}$ ).

Compared to the present $\mathrm{ZnO} / \mathrm{Ag}$ system, the $\mathrm{ZnO}$ bilayer on $\mathrm{Cu}(111)$ reported in ref 10 exhibits a much more pronounced buckling. We suggest that the much stronger interaction of $\mathrm{CO}$ with this buckled film (a binding energy of $0.54 \mathrm{eV}$ was found for $\mathrm{ZnO} / \mathrm{Cu}$ in ref 10 as compared to the binding energy of $0.24 \mathrm{eV}$ found for $\mathrm{ZnO} / \mathrm{Ag}$ in the present work) leads to a stronger back donation and an overall more red shifted $\mathrm{CO}$ frequency than in the present system. We note that a recent study by Tosoni et al. reported a red shift in the $\mathrm{ZnO} / \mathrm{Cu}$ system of similar magnitude as found experimentally for a film geometry that was flattened by artificial strain in the chosen supercell setup. ${ }^{39}$ Their computed binding energy largely underestimated the experimentally determined binding though. Tentatively, we therefore ascribe the agreement of their calculated frequency with experiment to a fortuitous under estimation of both the blue shifting Stark effect and the hybridization induced red shift.

\section{CONCLUSIONS}

As demonstrated by our experimental and theoretical results, the metal support plays a crucial role in the chemical activity of thin $\mathrm{ZnO}$ adlayers. The previously reported red shift by about $70 \mathrm{~cm}^{-1}$ for $\mathrm{CO}$ on $\mathrm{ZnO} / \mathrm{Cu}$ relative to the normal stretch frequency for $\mathrm{CO}$ on wurtzite surfaces is substantially modified when changing the metal substrate. In the $\mathrm{ZnO} / \mathrm{Ag}$ system we find a frequency similar to the gas phase $\mathrm{CO}$ vibrational frequency (red shifted by around $40 \mathrm{~cm}^{-1}$ with respect to wurtzite) for $\mathrm{CO}$ adsorbed on flat bilayer $\mathrm{ZnO}$ films and a frequency similar to previous results for wurtzite surfaces for $\mathrm{CO}$ adsorbed on thicker $\mathrm{ZnO}$ islands in the 3-4 $\mathrm{ML}$ range. Whereas on $\mathrm{Cu}$ the $\mathrm{ZnO}$ film has been reported to buckle substantially, we find that it adopts a flat graphitic like structure on Ag. This difference, which is driven by the different lattice constants of the two metals ( $3.61 \AA(\mathrm{Cu})$ vs $4.09 \AA(\mathrm{Ag}))$, has pronounced consequences for the adsorption energy of $\mathrm{CO}$, which is much decreased in the presence of an $\mathrm{Ag}$ substrate as compared to a $\mathrm{Cu}$ substrate. Our results thus illustrate the variety of $\mathrm{ZnO}$ phases that can be formed and the pronounced influence of the metal substrate for ultrathin $\mathrm{ZnO}$ films.

From the theoretical side, we have shown that GGA type DFT functionals cannot uncritically be applied to the study of $\mathrm{CO}$ adsorption on $\mathrm{ZnO}$. This is especially problematic for the wurtzite $\mathrm{ZnO}(1010)$ surface, where the incorrect level alignment results in a severe underestimation of the blue shift of the $\mathrm{CO}$ stretch frequency. $\mathrm{CO}$ binding energies, on the other hand, come out very similar at the hybrid and GGA levels. For $\mathrm{ZnO} / \mathrm{Ag}$, the frequencies seem to be much less sensitive to the errors in the level alignment, and good agreement with experiment is already obtained at the GGA level. Our analysis ascribes this difference to two effects: In contrast to the wurtzite $\mathrm{ZnO}(1010)$ surface, the work function is pinned by the metallic Fermi level, which is similarly described by both GGA and hybrid functionals. While this leads to a similar Stark contribution to the frequency shift, the hybridization with the surface is much weaker at the less corrugated $\mathrm{ZnO} / \mathrm{Ag}$ film. Functional errors in the frontier level positions are therefore less consequential, as the resulting different donation and back donation contributions to the overall frequency shift are smaller.

\section{AUTHOR INFORMATION}

\section{Corresponding Authors}

*E mail: mie.andersen@ch.tum.de (M.A.).

*E mail: yuemin.wang@kit.edu (Y.W.).

Mie Andersen: 0000000299431534 Yuemin Wang: 0000000299635473 Christof Wöll: 0000000310783304

Karsten Reuter: 0000000184738659

\section{Author Contributions}

${ }^{\S}$ M.A. and X.Y. contributed equally to this work.

\section{Notes}

The authors declare no competing financial interest.

\section{ACKNOWLEDGMENTS}

The authors gratefully acknowledge the Gauss Centre for Supercomputing e.V. (www.gauss centre.eu) for funding this project by providing computing time on the GCS Super computer SuperMUC at Leibniz Supercomputing Centre (www.lrz.de). Dr. Björn Bieniek is acknowledged for helpful 
discussions and for providing input structures for the DFT calculations. Funding from the "Science and Technology of Nanosystems" Programme (432202) is gratefully acknowl edged. X.Y. acknowledges the Ph.D. fellowships sponsored by the China Scholarship Council.

\section{REFERENCES}

(1) Freund, H. J.; Pacchioni, G. Oxide Ultra Thin Films on Metals: New Materials for the Design of Supported Metal Catalysts. Chem. Soc. Rev. 2008, 37, 2224-2242.

(2) Naumann d'Alnoncourt, R.; Xia, X.; Strunk, J.; Loffler, E.; Hinrichsen, O.; Muhler, M. The Influence of Strongly Reducing Conditions on Strong Metal-Support Interactions in $\mathrm{Cu} / \mathrm{ZnO}$ Catalysts Used for Methanol Synthesis. Phys. Chem. Chem. Phys. 2006, 8, 1525-1538.

(3) Sun, Y. N.; Giordano, L.; Goniakowski, J.; Lewandowski, M.; Qin, Z. H.; Noguera, C.; Shaikhutdinov, S.; Pacchioni, G.; Freund, H. $\mathrm{J}$. The Interplay between Structure and CO Oxidation Catalysis on Metal Supported Ultrathin Oxide Films. Angew. Chem., Int. Ed. 2010, 49, 4418-4421.

(4) Sonström, P.; Arndt, D.; Wang, X.; Zielasek, V.; Bäumer, M. Ligand Capping of Colloidally Synthesized Nanoparticles-A Way to Tune Metal-Support Interactions in Heterogeneous Gas Phase Catalysis. Angew. Chem., Int. Ed. 2011, 50, 3888-3891.

(5) Naumann d'Alnoncourt, R.; Friedrich, M.; Kunkes, E.; Rosenthal, D.; Girgsdies, F.; Zhang, B.; Shao, L.; Schuster, M.; Behrens, M.; Schlögl, R. Strong Metal-Support Interactions between Palladium and Iron Oxide and Their Effect on CO Oxidation. J. Catal. 2014, 317, 220-228.

(6) Willinger, M. G.; Zhang, W.; Bondarchuk, O.; Shaikhutdinov, S.; Freund, H. J.; Schlögl, R. A Case of Strong Metal-Support Interactions: Combining Advanced Microscopy and Model Systems to Elucidate the Atomic Structure of Interfaces. Angew. Chem., Int. Ed. 2014, 53, 5998-6001.

(7) Tauster, S. J. Strong Metal Support Interactions. Acc. Chem. Res. 1987, 20, 389-394.

(8) Kattel, S.; Ramírez, P. J.; Chen, J. G.; Rodriguez, J. A.; Liu, P. Active Sites for $\mathrm{CO}_{2}$ Hydrogenation to Methanol on $\mathrm{Cu} / \mathrm{ZnO}$ Catalysts. Science 2017, 355, 1296-1299.

(9) Lunkenbein, T.; Schumann, J.; Behrens, M.; Schlögl, R.; Willinger, M. G. Formation of a $\mathrm{ZnO}$ Overlayer in Industrial $\mathrm{Cu}$ / $\mathrm{ZnO} / \mathrm{Al}_{2} \mathrm{O}_{3}$ Catalysts Induced by Strong Metal-Support Interactions. Angew. Chem., Int. Ed. 2015, 54, 4544-4548.

(10) Schott, V.; Oberhofer, H.; Birkner, A.; Xu, M.; Wang, Y.; Muhler, M.; Reuter, K.; Wöll, C. Chemical Activity of Thin Oxide Layers: Strong Interactions with the Support Yield a New Thin Film Phase of $\mathrm{ZnO}$. Angew. Chem., Int. Ed. 2013, 52, 11925-11929.

(11) Schumann, J.; Kröhnert, J.; Frei, E.; Schlögl, R.; Trunschke, A. IR Spectroscopic Study on the Interface of $\mathrm{Cu}$ Based Methanol Synthesis Catalysts: Evidence for the Formation of a $\mathrm{ZnO}$ Overlayer. Top. Catal. 2017, 60, 1735-1743.

(12) Martynova, Y.; Liu, B. H.; McBriarty, M. E.; Groot, I. M. N.; Bedzyk, M. J.; Shaikhutdinov, S.; Freund, H. J. CO Oxidation over $\mathrm{ZnO}$ Films on $\mathrm{Pt}(111)$ at near Atmospheric Pressures. J. Catal. 2013, 301, 227-232.

(13) Pan, Q.; Liu, B. H.; McBriarty, M. E.; Martynova, Y.; Groot, I. M. N.; Wang, S.; Bedzyk, M. J.; Shaikhutdinov, S.; Freund, H. J. Reactivity of Ultra Thin $\mathrm{ZnO}$ Films Supported by $\mathrm{Ag}(111)$ and $\mathrm{Cu}(111)$ : A Comparison to $\mathrm{ZnO} / \mathrm{Pt}(111)$. Catal. Lett. 2014, 144, $648-655$.

(14) Naumann d'Alnoncourt, R.; Kurtz, M.; Wilmer, H.; Loffler, E.; Hagen, V.; Shen, J. Y.; Muhler, M. The Influence of $\mathrm{ZnO}$ on the Differential Heat of Adsorption of $\mathrm{CO}$ on $\mathrm{Cu}$ Catalysts: A Microcalorimetric Study. J. Catal. 2003, 220, 249-253.

(15) Freeman, C. L.; Claeyssens, F.; Allan, N. L.; Harding, J. H. Graphitic Nanofilms as Precursors to Wurtzite Films. Phys. Rev. Lett. 2006, 96, 066102 .
(16) Liu, B. H.; Groot, I. M.N.; Pan, Q.; Shaikhutdinov, S.; Freund, $\mathrm{H}$. J. Ultrathin $\mathrm{Zn}$ and $\mathrm{ZnO}$ Films on $\mathrm{Cu}(111)$ as Model Catalysts. Appl. Catal., A 2017, 548, 16-23.

(17) Kourouklis, H. N.; Nix, R. M. The Growth and Structure of ZnOx Overlayers on Low Index Silver Surfaces. Surf. Sci. 1994, 318, 104-114.

(18) Shiotari, A.; Liu, B. H.; Jaekel, S.; Grill, L.; Shaikhutdinov, S.; Freund, H. J.; Wolf, M.; Kumagai, T. Local Characterization of Ultrathin $\mathrm{ZnO}$ Layers on $\mathrm{Ag}(111)$ by Scanning Tunneling Microscopy and Atomic Force Microscopy. J. Phys. Chem. C 2014, 118, 2742827435 .

(19) Tusche, C.; Meyerheim, H. L.; Kirschner, J. Observation of Depolarized $\mathrm{ZnO}(0001)$ Monolayers: Formation of Unreconstructed Planar Sheets. Phys. Rev. Lett. 2007, 99, 026102.

(20) Deng, X.; Yao, K.; Sun, K.; Li, W. X.; Lee, J.; Matranga, C. Growth of Single and Bilayer $\mathrm{ZnO}$ on $\mathrm{Au}(111)$ and Interaction with Copper. J. Phys. Chem. C 2013, 117, 11211-11218.

(21) Stavale, F.; Pascua, L.; Nilius, N.; Freund, H. J. Morphology and Luminescence of $\mathrm{ZnO}$ Films Grown on a $\mathrm{Au}(111)$ Support. J. Phys. Chem. C 2013, 117, 10552-10557.

(22) Weirum, G.; Barcaro, G.; Fortunelli, A.; Weber, F.; Schennach, R.; Surnev, S.; Netzer, F. P. Growth and Surface Structure of Zinc Oxide Layers on a $\operatorname{Pd}(111)$ Surface. J. Phys. Chem. C 2010, 114, $15432-15439$

(23) Bieniek, B.; Hofmann, O. T.; Rinke, P. Influence of Hydrogen on the Structure and Stability of Ultra Thin $\mathrm{ZnO}$ on Metal Substrates. Appl. Phys. Lett. 2015, 106, 131602.

(24) Demiroglu, I.; Bromley, S. T. Evidence for Multi Polymorphic Islands During Epitaxial Growth of $\mathrm{ZnO}$ on $\mathrm{Ag}(111)$. J. Phys.: Condens. Matter 2016, 28, 224007.

(25) Wang, Y.; Wöll, C. IR Spectroscopic Investigations of Chemical and Photochemical Reactions on Metal Oxides: Bridging the Materials Gap. Chem. Soc. Rev. 2017, 46, 1875-1932.

(26) Merzlikin, S. V.; Tolkachev, N. N.; Strunskus, T.; Witte, G.; Glogowski, T.; Wöll, C.; Grünert, W. Resolving the Depth Coordinate in Photoelectron Spectroscopy - Comparison of Excitation Energy Variation Vs. Angular Resolved XPS for the Analysis of a Self Assembled Monolayer Model System. Surf. Sci. 2008, 602, 755-767.

(27) Scofield, J. H. Hartree Slater Subshell Photoionization Cross Sections at 1254 and $1487 \mathrm{eV}$. J. Electron Spectrosc. Relat. Phenom. 1976, 8, 129-137.

(28) Akkerman, A.; Boutboul, T.; Breskin, A.; Chechik, R.; Gibrekhterman, A.; Lifshitz, Y. Inelastic Electron Interactions in the Energy Range $50 \mathrm{eV}$ to $10 \mathrm{keV}$ in Insulators: Alkali Halides and Metal Oxides. Phys. Phys. Status Solidi B 1996, 198, 769-784.

(29) Tanuma, S.; Powell, C. J.; Penn, D. R. Calculations of Electron Inelastic Mean Free Paths. V. Data for 14 Organic Compounds over the 50-2000 eV Range. Surf. Interface Anal. 1994, 21, 165-176.

(30) Claeyssens, F.; Freeman, C. L.; Allan, N. L.; Sun, Y.; Ashfold, M. N. R.; Harding, J. H. Growth of $\mathrm{ZnO}$ Thin Films Experiment and Theory. J. Mater. Chem. 2005, 15, 139-148.

(31) Redhead, P. A. Thermal Desorption of Gases. Vacuum 1962, 12, 203-211.

(32) Blum, V.; Gehrke, R.; Hanke, F.; Havu, P.; Havu, V.; Ren, X.; Reuter, K.; Scheffler, M. Ab Initio Molecular Simulations with Numeric Atom Centered Orbitals. Comput. Phys. Commun. 2009, 180, 2175-2196.

(33) Perdew, J. P.; Burke, K.; Ernzerhof, M. Generalized Gradient Approximation Made Simple. Phys. Rev. Lett. 1996, 77, 3865-3868.

(34) Heyd, J.; Scuseria, G. E.; Ernzerhof, M. Hybrid Functionals Based on a Screened Coulomb Potential. J. Chem. Phys. 2003, 118, 8207-8215.

(35) Krukau, A. V.; Vydrov, O. A.; Izmaylov, A. F.; Scuseria, G. E. Influence of the Exchange Screening Parameter on the Performance of Screened Hybrid Functionals. J. Chem. Phys. 2006, 125, 224106.

(36) Tkatchenko, A.; Scheffler, M. Accurate Molecular Van der Waals Interactions from Ground State Electron Density and Free Atom Reference Data. Phys. Rev. Lett. 2009, 102, 073005. 
(37) Ruiz, V. G.; Liu, W.; Zojer, E.; Scheffler, M.; Tkatchenko, A. Density Functional Theory with Screened Van Der Waals Interactions for the Modeling of Hybrid Inorganic Organic Systems. Phys. Rev. Lett. 2012, 108, 146103

(38) Zhang, G. X.; Tkatchenko, A.; Paier, J.; Appel, H.; Scheffler, M. Van Der Waals Interactions in Ionic and Semiconductor Solids. Phys. Rev. Lett. 2011, 107, 245501.

(39) Tosoni, S.; Li, C.; Schlexer, P.; Pacchioni, G. CO Adsorption on Graphite Like $\mathrm{ZnO}$ Bilayers Supported on $\mathrm{Cu}(111), \mathrm{Ag}(111)$, and $\mathrm{Au}(111)$ Surfaces. J. Phys. Chem. C 2017, 121, 27453-27461.

(40) Bengtsson, L. Dipole Correction for Surface Supercell Calculations. Phys. Rev. B: Condens. Matter Mater. Phys. 1999, 59, 12301-12304.

(41) Fox, J. H.; Nuttall, J. D.; Gallon, T. E. Solid State Effects in the Auger Spectrum of Zinc and Oxidised Zinc. Surf. Sci. 1977, 63, 390402.

(42) Carley, A. F.; Roberts, M. W. Evidence for the Instability of Surface Oxygen at the $\mathrm{Zn}(0001) \mathrm{O} \mathrm{Cu}$ Interface from Core Level and $\mathrm{X}$ ray Induced Auger Spectroscopies. Top. Catal. 1996, 3, 91-102.

(43) Hansen, W.; Bertolo, M.; Jacobi, K. Physisorption of CO on $\mathrm{Ag}(111)$ : Investigation of the Monolayer and the Multilayer through HREELS, ARUPS, and TDS. Surf. Sci. 1991, 253, 1-12.

(44) Buchholz, M.; Yu, X.; Yang, C.; Heißler, S.; Nefedov, A.; Wang, Y.; Wöll, C. IR Spectroscopy of CO Adsorption on Mixed Terminated ZnO Surfaces. Surf. Sci. 2016, 652, 247-252.

(45) Wang, Y.; Xia, X.; Urban, A.; Qiu, H.; Strunk, J.; Meyer, B.; Muhler, M.; Wöll, C. Tuning the Reactivity of Oxide Surfaces by Charge Accepting Adsorbates. Angew. Chem., Int. Ed. 2007, 46, 73157318.

(46) Wöll, C. The Chemistry and Physics of Zinc Oxide Surfaces. Prog. Surf. Sci. 2007, 82, 55-120.

(47) Pacchioni, G.; Cogliandro, G.; Bagus, P. S. Characterization of Oxide Surfaces by Infrared Spectroscopy of Adsorbed Carbon Monoxide: A Theoretical Investigation of the Frequency Shift of $\mathrm{CO}$ on $\mathrm{MgO}$ and NiO. Surf. Sci. 1991, 255, 344-354.

(48) Yang, C.; Yu, X.; Heißler, S.; Nefedov, A.; Colussi, S.; Llorca, J.; Trovarelli, A.; Wang, Y.; Wöll, C. Surface Faceting and Reconstruction of Ceria Nanoparticles. Angew. Chem., Int. Ed. 2017, 56, 375-379.

(49) Blyholder, G. Molecular Orbital View of Chemisorbed Carbon Monoxide. J. Phys. Chem. 1964, 68, 2772-2777. 
Karlsruher Institut für Technologie

\section{Repository KITopen}

Dies ist ein Postprint/begutachtetes Manuskript.

\section{Empfohlene Zitierung:}

Andersen, M.; Yu, X.; Kick, M.; Wang, Y.; Wöll, C.; Reuter, K.

Infrared Reflection-Absorption Spectroscopy and Density Functional Theory Investigations of Ultrathin ZnO Films Formed on $\mathrm{Ag}(111)$.

2018. The journal of physical chemistry <Washington, DC > C, 122

doi:10.1021/acs.jpcc.8b00158

Zitierung der Originalveröffentlichung:

Andersen, M.; Yu, X.; Kick, M.; Wang, Y.; Wöll, C.; Reuter, K.

Infrared Reflection-Absorption Spectroscopy and Density Functional Theory Investigations of Ultrathin ZnO Films Formed on $\mathrm{Ag}(111)$.

2018. The journal of physical chemistry <Washington, DC> / C, 122 (9), 4963-4971.

doi:10.1021/acs.jpcc.8b00158 